EESTI NSV TEADUSTE AKADEEMIA TOIMETISED 1953. II k., nr. 4 ИЗВЕСТИЯ АКАДЕМИИ НАУК ЭСТОНСКОИ ССР 1953. ТоМ II, 수 4

\title{
ИССЛЕДОВАНИЯ МИГРАЦИИ ПТИЦ В ОРНИТОЛОГИЧЕСКОИ СТАНЦИИ ПУХТУ
}

\author{
Э. В. КУМАРИ,
}

доктор бнологнческих наук

Со времени появления первых классических работ о пролетных путях птиц $(19,20)$ накопнлось много нового материала, дающего возможность разрешить некоторые «загадки» миграции птиц. Так, выяснилось, что строго ограниченных пролетных путей в Прибалтике не существует, скорее наоборот - большинство птищ летит над этой территорией широким фронтом $\left({ }^{5}\right)$. Новейшие исследования отечественных $\left({ }^{8}, 12\right)$ и зарубежных орнитологов $\left({ }^{15,18}\right)$ свидетельствуют о том, что пролетные пути птиц являются весьма условными категориями. Поэтому более уместно говорить об общих направлениях пролета, в рамках которых, в зависимости от ландшафтных условий, встречаются как пролетные пути, так и пролеты широким фронтом. Некоторые северные кулики, которых Пальмен $\left({ }^{20}\right)$ счнтал типичными мигрантами морского побережья, по новейшим данным, регулярно пролетают также и через внутренние районы Прибалтики.

Тем не менее имеется ряд водяных и прибрежных птиц, связь которых с побережьем Балтики все же совершенно очевидна. Главная их масса, встречаясь также и внутри страны, предпочитает пруи пролете через Прибалтику приморские районы или морское побережье и море, Если мы проследим пути следования таких видов птиц, то увидим, что их пролетный поток направляется с более южных частей Балтийского моря через западные острова и проливы Эстонии в Финский залив, а оттуда вдоль многочисленных озер Южной Карелии на Белое море и Северный Ледовитый океан. Такая совоқупность пролетов морских и прибрежных птиц, имеющих основное направление с юго-запада на северо-восток, уже в прошлом столетии получила название Беломорско-Балтийского пролетного пути. Этот путь в действительности является широкой магистралью следования многих водяных птиц. Спещиальными исследованиями доказано, что на этом пути весенний и осенний пролеты имеют не только различную интенсивность, но отчасти и разные виды на различных отрезках пути. Если взять путь в целом, то надо отметить, что осенний пролет является гораздо более оживленным, чем весенний.

На Беломорско-Балтийском пролетном пути численность перелетных птиц осенью возрастает в направлении с северо-востока на юго-запад. В Южной Карелии, по данным Семенова-Тян-Шанского $\left({ }^{9}\right)$, величина осеннего пролета мало соответствует представлению о пролетном пути. По мнению этого автора, главная масса птиц летит над территорией Южной Карелии вдоль берегов более значительных водоемов, обходя область водораздела. Однако уже на Финском заливе численность мнгрантов зна- 
чительно возрастает, а кроме того, существует и хорошо выраженный пролетный поток через внутренние районы Эстонии. По подсчетам автора (5), из всех пролетных видов, встречающихся в нашей республике, 35 видов являются массовыми (по крайней мере периодически), причем из них почти $50 \%$ (17 вндов) составляют гусеобразные.

В свое время Гроссе $\left({ }^{17}\right)$ предполагал с известной долей вероятности, что главные пролетные магистрали птиц через Латвию идут в трех направлениях: 1) вдоль морского побережья Курземе, 2) от Чудского озера на Ригу и Лиепая и 3) от Чудского озера на Западную Двину и Литву. Позднее Богданович $\left({ }^{14}\right)$, изучая осенний пролет птиц на Рижском взморье, выяснил, что и там происходит оживленный пролет. Птицы летят как вдоль морского побережья, так и прямо над морем, при этом в первой половине октября имеются дни, когда птицы пролетают большими массами. Отсюда птицы, повидимому, летят в юго-западном направлении, так как, по данным Тинемана $\left({ }^{24}\right)$, в западной части Латвии (Курземе) осенний пролет птиц весьма незначителен.

Наиболее грандиозен осенний пролет на западном побережье Литвы $\left({ }^{4}\right)$ и в северо-восточном районе Калининградской области $\left({ }^{23}\right)$. Птицы, продвигаясь широким потоком с северо-востока, сосредоточиваются на узких пролетных путях на берегах Курского залива и вдоль косы Неринги, а затем вновь рассеиваются. Самый напряженный пролет пронсходит здесь в октябре, когда у Вентес Рагас общее количество пролетающих скворцов доходит до 100 тысяч особей в день, а общая сумма всех пролетающих в Росситтене птиц за день достигает иногда полумиллиона.

Такова общая картина, которую мы нмеем в результате сравнения осенних пролетов птиц на разных отрезках Беломорско-Балтийского пролетного направления.

Изучение миграции птиц в Эстонской ССР до сих пор проводилось от случая к случаю. Учитывая необходимость углубления знаний по перелетам птиц на территории Эстонской ССР и общую важность этого вопроса во всесоюзном масштабе, Институт зоологии и ботаники Академин наук Әстонской ССР в 1952 году приступил к планомерному изучению мигращии птиц на западном побережье республики. Базой для этих работ служит орнитологическая станция Института в Пухту около Виртсу, удобно расположенная в месте пролета многих морских и прибрежных птиц. Эти работы находятся еще в начальной стадии, станция пока еще не имеет необходимого для всестороннего изучения мигращии птиц оборудования, однако даже первые результаты все же представляют некоторый интерес.

Более планомерные наблюдения удалось провести главным образом во время пролета гусеобразных, поэтому автор считает возможным коснуться в настоящей статье только представителей этого отряда. Изучение этой группы представляет также практический интерес, так как по численности особей эта группа стоит на первом месте среди морских мигрантов.

Интенсивность пролета водоплавающих на Балтийском море в разных его частях не одинакова. В западной части Балтики, у южной оконечностн острова Эланд, по данным Эдельштама $\left({ }^{16}\right)$, осенью пролетает разных видов уток обшим количеством 40-70 тысяч особей, причем свиязь составляет среди этих мигрантов около $20 \%$. Гроссе $\left({ }^{17}\right)$ наблюдал в Латвии в октябре и ноябре на крупных приморских озерах большие стаи нырковых уток (гоголь, хохлатая и морская чернеть), насчитываюшие более 10 тысяч особей. На Выборгском заливе, по подсчетам Путконена $\left({ }^{21}\right)$, общая сумма всех пролетающих весной особей синьги, морянкн, турпана и других водоплавающих птиц превышает миллион. Таким обра- 
зом, в разных частях Балтийского моря пролет гусеобразных имеет различную численность и различный видовой состав,

Изучение видовых и количественных соотношений пролетающих у берегов Эстонии утиных, а также различий в их весеннем и осеннем пролете требует количественного метода работы. Поэтому приведенные ниже соответствующие цифровые подсчеты, пронзведенные нами осенью 1952 и весной 1953 годов на проливе Мухувяйн между эстонским материком и западными островами, должны представлять некоторый ннтерес.

Л ебед ь-кликун Cygnus cygnus (L.). В окрестностях Виртсу и на заливе Матсалу почти ежегодно пролетают два вида - лебедь-кликун и малый лебедь. Различить их в полевых условиях с полной достоверностью не всегда удается. Все данные о лебедях, даваемые в настоящей статье, должны быть отнесены к обоим видам совместно. В Эстонии лебеди пролетают с марта до середины мая и с октября по декабрь, причем весенний пролет почти всегда бывает более оживленным. Весенний пролет в 1953 году на проливе Мухувяйн и на заливе Матсалу оказался весьма интенсивным, причем птицы долгое время держались на тихих заливах. Численность особей в отдельных стаях была различной - от нескольких до нескольких сотен особей. В первой половине апреля выпадали дни, когда общее количество лебедей на заливе достигало более 10 тысяч особей. В полдень 7 апреля в литоральных водах южного побережья залива мы наблюдали на участке около $1,5 \times 0,5$ кв. км громадную стаю приблизительно из 5 тысяч лебедей. Еще в середине мая около 500 лебедей останавливалось во внутренней части залива. Общее количество пролетевших этой весной через пролив Мухувяйн лебедей, по нашим подсчетам, равнялось нескольким десяткам тысяч особей.

C ер й г у сь Anser anser (L.). Оживленного пролета серых гусей здесь не бывает вследствне того, что Эстония расположена вблизи северной границы ареала этого вида $\left({ }^{2}\right)$. В окрестностях Виртсу осенью и весной наблюдались лишь кочующне стайки из нескольких особей, представляющие собой, повнднмому, гнездовых птиц залива Матсалу и приморских озер.

Белолобая казарка Anser albifrons (Scop.) Пролетает регулярно, но немногочисленными стаями. Осенью встречается гораздо реже, чем весной. Стаи, численностью от 5 до 70 особей каждая, были отмечены главным образом с середины мая, причем они редко делали остановки в окрестностях Виртсу. Места скопления на остановках больших количеств белолобых казарок в Эстонии, как и в других Прибалтийских странах, повидимому, нензвестны. Остановка этого вида в мае месяце в количестве 2-2,5 тысяч особей у Рыбннского водохранилища (сообщение Третьякова $\left.\left({ }^{10}\right)\right)$ является, пожалуй, исключительным случаем.

Гу у енни к Anser fabalis (Lath.). Учитывая широкое распространение гуменника на севере евразийского материка (см. карту у Тугаринова $\left.\left({ }^{11}\right)\right)$, его валовой пролет через Прибалтику совершенно понятен. Из всех гусей и казарок гуменник и здесь является наиболее многочисленным пролетным видом и встречается по всей республике. Основной пролет его в Эстонии происходит в апреле и октябре. Этот вид при пролете над Эстонией не прндерживается западного побережья. Он здесь гораздо более малочнслен, чем в некоторых районах центральной и юго-восточной Эстонии. Ежегодно осеньі и весной он использует для остановок обширные приморские луга между Виртсу и устьем залива Матсалу на восточном побережье пролива Мухувяйн. Весной 1953 года он был значительно более многочислен, чем осенью предыдущего года, однако общее количество особей гуменника, пролетавших вдоль восточного берега пролива Мухувяйн этой весной, едва ли намного превысило тысячу особей. 
Гуменник численно преобладает над всеми другими гусями также и в Калининградской области $\left({ }^{25}\right)$, в западной Латвии (17) и на Рижском взморье $\left({ }^{14}\right)$. В то же время на Выборгском заливе число особей в стае редко превышает $15\left({ }^{21}\right)$.

Черн а я казарка Branta bernicla (L.). В предыдущие годы этот вид изредка встречался на пролете в окрестностях Виртсу и залива Матсалу, но за 1952-1953 годы никаких данных о нем не имеется. Распределение пролета черной казарки в восточной Балтике интересно тем, что в ее южных частях (Қалининградская область, Латвия) черная казарка встречается в весьма малом количестве, в то время как на Финском заливе имеет место весьма оживленный пролет ее. По данным финской литературы, весенний пролет, совершающийся в мае, а в некоторых случаях даже и в июне, часто состоит из стай численностыю в $300-500$ особей каждая. Регулярно этот вид пролетает также через море около Таллина. В отдельные годы (например, в 1931 году) одиночные особи залетали даже далеко внутрь материковой Эстонии, что известно и из Калининградской области $\left({ }^{25}\right)$. Черная казарка, зимующая в массовых количе ствах на Северном море, при своем пролете через Балтику пересекает среднюю часть Ботнического и Финского заливов.

Белощекая каз а р ка Branta leucopsis (Bechst.). Многочислен ный пролетный вид (в частности, весной) около Виртсу и залива Матсалу. В 1953 году более крупные стаи появились около 20 апреля, постепенно их количество увеличивалось, и в первой половине мая на приморских лугах залива Матсалу останавливались стаи чнсленностью до 500 600 особей каждая. На морских островах около Виртсу эти птищы останавливались довольно редко; прямой пролет наблюдался почти каждый день. В течение одного месяца через пролив Мухувяйн пролетали, по всей вероятности, многие тысячи особей. Откуда они прилетели, этот вопрос остается неясным. Белощекая казарка появляется в большом количестве в районе наших наблюдений и весной совершает здесь длительные остановки. Как известно, на взморье юго-восточной Балтики упомянутый вид встречается лишь изредка, являясь также весьма немногочисленным и в восточной части Финского залива. Возможно, что пролетный путь белощекой казарки пересекает Балтийское море вдоль его больших островов и от западной Эстонии берет направление прямо на север.

С в и я з ь Anas penelope L. Свиязь занимает по численности первое место среди всех настояших уток, пролетающих осенью и весной в окрестности Виртсу. В сентябре-октябре и апреле-мае происходит ее валовой пролет в количестве многих десятков тысяч особей. Количественный учет вида связан с большими трудностями, так как пролетные стаи рассеяны вдоль всего пролива Мухувяйн и его многочисленных заливов.

К расноголовы й нырок Nyroca ferina (L.) и хохлатая ч ер не т ь Nyroca fuligula (L.). Оба вида связаны с литоральными водами, в частности с тихнми залнвами, и избегают открытого моря. В октябре и ноябре 1952 года они встречались сравнительно мало, а в апрелемае 1953 года останавливались около Виртсу и на заливе Матсалу стаями в несколько сот особей. При этом стаи эти часто соединялись в общие стаи, где численные соотношения первого вида ко второму составляли приблизительно 1:2. Самшы всегда оказывались в большом перевесе. Oсобенно это бросалось в глаза у красноголового нырка, число самцов у которого во много раз превышает число самок. Во второй половине апреля и в начале мая на заливе Раме у Пухту постоянно держалась стая из нескольких сот особей. Ни прилета новых особей, ни отлета особей из этой стаи не было заметно. Птицы уже ранней весной сбились в пары, холостые особи также держались в этой общей стае. Такая длительная 
остановка этих нырковых уток позволяет предположить, что в данном случае имелась гнездовая популяция недалеких окрестностей.

Mорская чер н е т Nyroca marila (L.). Осенью и в особенности весной это одна из наиболее многочисленных пролетных нырковых уток на западе Эстонии. По данным Зарудного (1), она многочисленна также на Псковском озере. На пролете около Виртсу встречалась в октябре ноябре и в апреле-мае. Внд держится у побережья только во время штормов, залетая даже в тихие заливы, в остальное же время предпочитает открытое море, где встречается стаями от нескольких десятков до тысячи особей каждая. Численность особей в стаях велика, в частности весной, когда уже со времени появления первых пролетных стай птищы соединяются в пары. В конце апреля и в начале мая 1953 года общее количество морских чернетей вдоль восточной части пролива Мухувяйн (от устья залива Матсалу до залива Вайсте) определялось в $50-80$ тысяч особей.

Откуда пронсходят эти большие массы пролетных морскнх чернетей, сказать трудно, ибо кольцевание этого вида проводилось до сих пор в очень незначительном количестве. В юго-восточной части Балтики, по данным Тишлера $\left({ }^{25}\right)$, морская чернеть также встречается в большом количестве, однако весной реже, чем осенью. Напротив, на внутренних водоемах Калининской области $\left({ }^{3}\right)$ валовой пролет ее замечен в последней декаде апреля; в это время она значительно преобладает над хохлатой чернетью.

Г о г о л Bucephala clangula (L.). В течение весеннего и осеннего пролетных периодов гоголь является самой многочисленной (не считая синьги) водяной птицей на западном побережье республики. Вместе с морянкой он является также и самой первой из прилетающих и самой последней из отлетающих нырковых уток. По нашему подсчету, общее количество пролетающих осенью и весной. через пролив Мухувяйн гоголей равняется нескольким сотням тысяч особей. Вид останавливается как на открытом море, так и в литоральных водах. Более точный учет его численности затруднен вследствие большой рассеянности пролетных стай.

Пронсхождение зимуюших и пролетающих в большом количестве над Балтийским морем гоголей трудно установить, так как находок окольцованных гоголей имеется пока слишком мало. Местные гнездовые гоголисамцы исчезают из свонх гнездовых участков уже в конще весны, а в ЈОжной Карелии, по данным Семенова-Тян-Шанского $\left({ }^{9}\right)$, отлет самцов пронсходит в нюле. Часть гнездовой популяции Западной Сибири откочевывает осенью прямо в западном направлении, попадает в Белое море и через Скандинавию дальше в Западную Европу $\left({ }^{7}\right)$; однако на Балтийском море пока неизвестно ни одной находки-окольцованного в Западной Снбири гоголя. Весной во всех частях Балтики пролетные массы гоголя уменьшаются около середины апреля и к конщу этого месяца их остается совсем мало. Следует предположить, что родина здешних пролетных гоголей находится в западной части таежной зоны нашей страны.

Mорянка Clangula hyemalis (L.). В окрестности Виртсу морянка по численности сильно уступает синьге, гоголю и морской чернети. Даже на весеннем пролете, когда ее численность более высока, редко встречаются стаи, превышающие несколько десятков особей. Вся пролетная масса ее разборосана по всему проливу Мухувяйн и держится в открытом море. Общая сумма особей морянки, пролетевшей через Мухувяйн весной 1953 года, была не больше чем 5-6 тысяч особей. В то же время мы знаем, что хорошей весной на некоторых заливах в окрестности Таллина можно за один день насчитать значительно больше 10 тысяч особей морянок. Это свидетельствует о том, что большие массы пролетаюших над 
Финским заливом морянок летят сюда огибая острова Саарема и Хийума, минуя проливы западной Әстонин.

Морянка, повндимому, летит весной со своих зимовок на южной Балтике прямо на север и в устье Финского залива поворачивает на восток. В окрестности Хельсинки главный пролет происходит в конще апреля-начале мая, причем бывают случан, когда в день пролетает до 40 тысяч морянок $\left({ }^{13}\right)$. Путконен $\left({ }^{21}\right)$ оценивает общую сумму пролетающих весной на Выборгском заливе в восточной части Финского залнва морянок в несколько сотен тысяч особей. Главный пролет пронсходит здесь во второй половине мая. Как показывают данные кольцевания $\left({ }^{6}\right)$, по меньшей мере у части зимующих и пролетающих на Балтийском море морянок родина лежит далеко на северо-востоке (до полуострова Ямал включительно). Наряду с синьгой морянка является главным видом перелетных птиц Беломорско-Балтийского пролетного пути.

С и нга Oidemia nigra (L.). Из всех водоплавающих Балтийского моря синьга, несомненно, имеет наиболее интересную картину пролета. Места зимовок ее находятся главным образом на морях Западной Европы, частью же на южной Балтике $(2,11)$. О массовом пролете в юго-восточной части Балтийского моря Тишлер $\left({ }^{25}\right)$ не упоминает, а Гроссе $\left({ }^{17}\right)$ сообщает лишь об ее многочисленном осеннем пролете в западной Латвии. Также неизвестны тысячные стаи синьги и в южной части Рижского залива (устное сообщение Э. Я. Таурнньша).

Однако при приближении к западным берегам Эстонии картина меняется. Вид становится все более и более многочисленным, в особенности на весеннем пролете, и уже через пролив Мухувяйн совершается его массовый пролет.

Особенно оживленным является весенний пролет синьги. Первые стан появляются уже в первой половине апреля, а к концу этого месяца они становятся обыкновенным явлением на море между островом Саарема и западным побережьем материковой Эстонии. Синьга почти всегда держится далеко от берегов, в открытом море. Начиная со второй декады мая пролетные массы приходят в движение, наступает старт весеннего отлета на гнездовья. Такой отлет совершается в теченне нескольких дней. Все небо покрывается бесконечными шеренгами из нескольких десятков до нескольких сотен синьги, которые летят высоко $(200-500$ м) и без остановок в северном направлении. Весенннй отлет начинается обычно вечером и продолжается до поздней ночи. По наблюдениям сотрудников орнитологической станции Пухту 3. А. Сави и О. Я. Ренно, весной 1952 года в течение 7 дней (самый оживленный пролет от 22 до 24 мая) у Пухту пролетело через узкую полосу приблизительно в 2 км свыше 200 тысяч особей синьги. Весной 1953 года отлет синьги начался вечером 13 мая, но протекал менее интенсивно. Каждый вечер над Пухту пролетало от 3 до 8 тысяч особей.

Такую же картину весеннего пролета синьги описывают Бергман (13) у Хельсинки и Путконен (21) у Выборга. На Финском заливе этот внд достигает своей наивысшей численности, пролетая у Хельсинки в количестве до 30 тысяч особей за один вечер, а на Выборгском заливе в течение всего сезона - сотнями тысяч особей. Как установил Бергман, стимулом весеннего отлета синьги являются особые атмосферные условия в более высоких слоях воздуха. Отлет синьги увлекает за собой и перелетные массы морянок.

Синьга является в основном морским мигрантом, однако некоторые стаи ее все же пролетают глубоко внутри страны, например в Финляндии $\left({ }^{2}\right)$ и в Калининской области $\left({ }^{3}\right)$. На внутренних водоемах Эстонии 
также время от времени встречаются отдельные более мелкие стайки снньги.

На осеннем пролете синьга, являясь не менее многочисленной, придерживается иного порядка мигращии. На Финском заливе стаи старых самцов появляются уже с самого начала июля, а главный пролет происходит в августе. В это время пролетные стаи проносятся одна за другой в западном направлении над бесчисленными мысами северной Эстонии, Самки и молодые птицы следуют за ними только в октябре и ноябре.

Таким образом, есть основание предполагать, что пролетные потоки синьги в оба пролетных сезона летят большей частью прямо из средней части Балтийского моря в Финский залив и обратно, и только часть их залетает в северную часть Рижского залива и отсюда через пролив Мухувяйн летит в северном направлении. Однако даже и эта часть составляет на наших западных проливах такую значительную массу, что в известные годы синьга превышает численностью даже гоголя.

\section{Выводы}

Выше приведен только материал по миграцин наиболее многочисленных или нанболее характерных пролетных водоплавающих птиц, наблюдаемых в окрестности орнитологнческой станции Пухту. Этот пока еще весьма неполный материал все же показывает, что местоположение эстонской орнитологической станщин вполне прнгодно для развертывания дальнейших более углубленных исследований по миграции птиц на базе станцин.

Пролет северных гусеобразных на проливе Мухувяйн проходит достаточно интенсивно. В весеннем и осеннем пролетах птиц имеются различия в видовом составе и в количестве особей, но более четко характер этих различнй можно будет установить в результате будущих планомерных нсследований.

Важнейшнми пролетными видами на проливе Мухувяйн являются лебедь-кликун, свиязь, морская чернеть, гоголь и синьга. Қаждый из этих видов, взятый в отдельности, пролетает в массах, насчитывающих десятки и даже сотни тысяч особей. Общая сумма пролетевших весной 1953 года через пролив Мухувяйн водоплавающих птиц составляет около 1 мнллиона особей.

Видовой и количественный состав пролетных птиц в различных частях Балтийского моря нмеет явные различия. В устье Финского залива пути пролета разных видов птиц осенью разветвляются и потоки мигрантов направляются в юго-западном и южном направлениях. Весной же этот пункт является местом сосредоточения птиц, прибывающих из разных направлений.

Происхождение пролетающих над эстонским материком водоплавающих, в том числе жчисто морских» птиц, остается неясным. Пролет широкнм фронтом является в Прибалтике общим правилом, однако часть водоплавающих более морской диспозиции предпочитает западные приморские районы территорин, где эти виды встречаются в гораздо большем количестве, чем на востоке. 
1. Н. 3 а р у дны й, Птицы Псковской губернии. Зап. имп. Акад. наук, т. 25, N. 2 . 1910.

2. Ю. А. Исаков и Е. С. Птушен ко, Отряд гусеобразных. Птншы Советского Союза, т. 4, Москва, 1952.

3. Ю. А, Н са ков и $М$. П. Р а спопов, Матерналы по экологии водоплавающих птиц Молого-Шекснинского междуречья до образования водохранилища. Тр. Дарвинск, гос. зап., вып, I, 1949.

4. Т. Л. Иванаускас, Перелеты птиц в Литве. Зоологический журнал, 31 . вып, 6, 1952.

5. Э. В. К у м а р и, Пролет и зимовка птиц и задачи их нсследования на территорни Эстонской ССР. Сборник жПерелеты птиц в Европейской части СССР». Pura, 1953.

6 А. В. Мн хе ев, О сезонных перелетах морянки. Труды Центр. бюро кольцевания, вып. 6, 1947.

7. А. В. Ми хеев, Сезонное размещение и миграцин нырковых уток. Труды Центр. бюро кольцевания, вып, 7,1948 .

8. А. Н. П ром птов, Сезонные миграции птиц, Москва-Ленинград, 1941.

9. О. Семенов-Т ян-Ш анский, О пролете птиц в Қарелии. Зоологический журнал, 26 , вып, $3,1947$.

10. Н. Н. Т реть яков, К изучевию миграции и гнездований птиц Рыбинского водохранилища в 1945 году. Тр. Дарвинск, гос, зап,, вып. I, 1949.

11. А. Я. Тугаринов, Пластинчатоклювые. Фауна СССР. Птицы, т. I, вып. 4, Москва-Ленинграл, 1941.

12. А. Я. Тугаринов, Современное состояние учения о сезонных миграциях птиц. Изд. АН СССР, сер. биол., № I, 1949.

13. G. Bergman, Der Frühlingszug von Clangula hyemalis und Oidemia nigra bei Helsingfors. Orn. Fenn., 18, Nr. I, 1941.

14. H. Bogdanowicz. Planbeobachtung des Vogelzuges in Bullenhof-Dünamünde, Herbst 1935, Schr. der Phys.-ökon. Ges. zu Königsberg. 69. Heft 2-4, 1936.

15. R. Drost, Study of Bird Migration 1938-1950. Proceedings of the X-th International Ornithological Congress. Uppsala, 1951.

16. C. Edelstam, The Ottenby Bird Station. Proceedings of the X-th International Ornithological Congress. Uppsala, 1951.

17. A. Grosse, Vogelzugbeobachtungen. Korr.-Bl. des Nat.-Ver. zu Riga, Bd. 59, 1927.

18. J. Hortling, Das Vogelleben bei Ytterö im Sommer und Herbst 1926. Helsingfors, 1927.

19. M. Menzbier, Die Zugstrassen der Vögel im europaeischen Russland. Bull. de la Soc. des nat. de Moscou, Nr. 2, 1886.

20. J. A. P a I m é n, Ueber die Zugstrassen der Vögel. Leipzig, 1876.

21. T. A. Putkon e n, Kevätmuutosta Viipurinlahdella. Orn. Fenn., 19, Nr. 2, 1942.

22. A. Py nnönen, Uber den Zug der Trauerente, Oidemia n. nigra (L.), im Innern Finnlands. Orn. Fenn., 18, Nr. 1, 1941.

23. E. Schüz, Die Verteilung des Herbst-Vogelzuges im Gebiet des Kurischen Haffs. Die Naturwissenschaiten, 18, 1930.

24. J. Thienemann, Bericht über eine kurze Studienreise nach Kurland. Journ. f. Orn., 65, Heft 3, 1917.

25. F. Tischler, Die Vögel Ostpreussens und seiner Nachbargebiete. Königsberg und Berlin, 1941. 